\title{
Can a decline in the population means of cardiovascular risk factors reduce the number of people at risk?
}

\author{
U Laaser, J Breckenkamp, A Ullrich, B Hoffmann
}

\begin{abstract}
Objective-To prove the possibility of shifting distribution of cardiovascular risk factors for a whole population over time and thereby to influence the prevalence of the corresponding disease states, according to the theory stated by Geoffrey Rose in 1985.

Design-Examination of standardised data from the German Cardiovascular Prevention Study (GCP), a seven year long, population-based, multicentre intervention trial, concerned with decreasing risk factors for cardiovascular disease.

Setting and subjects-three cross sectional surveys of a population 25 to 69 years old in six study regions, and three nationwide cross sectional surveys in the former West Germany in 1984, 1988 and 1991.

Main outcome measures-The relation between the population mean for systolic and diastolic blood pressure, total serum cholesterol, body mass index, and alcohol intake, and the prevalence of the corresponding disease states, as are systolic $(\geqslant 140$ and $\geqslant 160 \mathrm{~mm} \mathrm{Hg}$ ) and diastolic hypertension ( $\geqslant 90$ and $\geqslant 95 \mathrm{~mm} \mathrm{Hg}$ ), hypercholesterolaemia $(\geqslant 250$ and $\geqslant 300$ mg/dl), overweight (body mass index $\geqslant 30$ $\mathrm{kg} / \mathrm{m}^{2}$ ), and heavy drinking (weekly alcohol intake $\geqslant 300 \mathrm{~g} /$ week). Results are expressed as linear regression equations and Pearson correlation coefficients.

Results-The correlation between the mean population values and prevalence of disease was close for blood pressures and body mass index. The Pearson coefficients, corrected for the influence of values increased above borderlines, were 0.86 and 0.81 respectively for systolic blood pressure, 0.88 and 0.91 for diastolic blood pressure, 0.28 and 0.52 for cholesterol, and 0.86 for the body mass index. The coefficient for alcohol intake was 0.55 . Conclusions-It seems possible to shift the risk distribution of a population for some physiological parameters over time with the effect of changing the disease prevalence. This strategy can be used successfully for specific preventive measures, as was strongly advocated by Geoffrey Rose. ( $F$ Epidemiol Community Health 2001;55:179-184)
\end{abstract}

Arterial hypertension was proved to widely vary among different geographical regions as well as among different cultural settings. While nomads in Kenya ${ }^{1}$ and the Yanomamo Indians in Brazil hardly know this disease, it is quite common in the Western industrialised world. ${ }^{2}$

By looking at the distribution of blood pressure values of these populations, you can see that not only the number of people in the abnormal range differs, but that the whole distribution curve is shifted as well. In this case, the population means of blood pressure and the prevalence of disease states of these-that is, hypertensive blood pressure-will correlate.

In 1990 Geoffrey Rose examined the relation between the population means of several health indicators, like blood pressure, body mass index, alcohol intake and sodium intake, and the corresponding prevalence rates of disease states operationally defined as being above certain values. Using data from a large intercultural epidemiological study (Intersalt) with 52 distinct populations, ${ }^{2}$ Rose and Day $^{3}$ showed that the population means for physiological as well as for behavioural parameters have an almost linear relation to the prevalence of the corresponding disease states. In this intercultural comparison, populations with higher means also had higher prevalence rates of the diseases. From these results, the authors drew the conclusion that it is possible to predict the number of diseased people in a given population from the mean of the corresponding health indicators in the same population. They stated that the tail of the risk distribution - that is, the high risk people - belongs to its body - that is, to the "normal" ones. Therefore, they emphasised the collective responsibility of the society for the number of its deviant people.

From this concept, two main preventive strategies can be deduced. The commonly used and traditional strategy in clinical medicine that consists of identifying people at high risk to be treated with appropriate means to reduce individual susceptibility. While this offers a favourable benefit to risk ratio to the patient and makes a cost effective use of medical resources, the underlying causes of the incidence rate within a population are not tackled.

Its aim is to cut off the high end tail of a population's risk distribution by treating only those susceptible to a certain disease.

This so called high risk strategy contrasts with the population strategy, where one tries to change the behaviour or characteristics of the whole population. To this aim, the risk distribution of the entire population has to be moved to a lower risk range. This is a radical approach that has an unexpectedly high potential of prevention for the population, but on the 
other hand offers only a small benefit to risk ratio to each person. The immediate benefit of the high risk approach can be appreciated easily by the patient and the doctor. The population strategy, however, lacks a large benefit for most people, who would have been well anyway. Its great advantage and challenge lies in the attempt to change the view of what is normal within a population by accepting the population's responsibility for those with deviant values. ${ }^{45}$

So far, the underlying theory has been proved only by intercultural comparison of observational data. This paper attempts to add one more piece of evidence to the relation between induced changes of the population mean and prevalence of disease within a population over time. Therefore, the hypothesis of Rose was tested in an intervention study ${ }^{\star}$. To this end, we make use of the multiple regional and national surveys in the German Cardiovascular Prevention Study (GCP). ${ }^{6}$

\section{Methods}

The GCP was a seven year long, populationbased, multicentre intervention trial aiming at reducing risk factors for cardiovascular diseases. In addition to a high risk approach to prevention, a population strategy was also applied. Broad preventive programmes were implemented in overlapping waves in six regions in West Germany. The programmes consisted of educational, behavioural, and medical advice on eating and drinking habits, early detection of hypertension and hypercholesterolaemia, exercise, non-smoking campaigns, and stress reduction. For further information on the design refer to the GCP Study Group $^{7}$ and Forschungsverbund DHP (Hrsg).

* Our paper follows closely the famous publication of Geoffrey Rose in $1990,{ }^{3}$ we therefore devote it to his memory.
From a total population, aged 25 to 69 , three cross sectional representative surveys have been sampled (see the tables in appendices 1 and 2) in each of the six intervened regions (Regional Health Surveys) as well as from the former West Germany as a whole (excluding the intervention regions) providing the reference population (National Health Surveys): at baseline (1984), midpoint (1988), and at the end of the programme (1991). The response rates for the national samples varied between $66.7 \%, 71.4 \%$, and $69.0 \%$ respectively, and for the pooled intervention samples between $74.5 \%, 73.0 \%$, and $71.6 \% .^{6}$ For statistical analyses a weighting factor based on the census data of 1987 was applied to adjust for slight deviations in the national samples of the intended age, sex, community size and federal state distribution. ${ }^{6}$ Among others, measurements of arterial blood pressure, cholesterol, and body mass were taken. Behavioural items included daily alcohol intake.

The population mean values of each of the three measurements have been calculated for each region and the national survey regarding the following parameters: systolic blood pressure, diastolic blood pressure, total serum cholesterol, body mass index, and weekly alcohol intake.

Abnormal deviance for the purpose of this analysis - also in order to be comparable with Rose and Day ${ }^{3}$ - is defined as follows (for comparison see also the centiles in appendix 2): systolic hypertension as systolic blood pressure $\geqslant 140$ and $\geqslant 160 \mathrm{~mm} \mathrm{Hg}$, diastolic hypertension as diastolic blood pressure $\geqslant 90$ and $\geqslant 95 \mathrm{~mm} \mathrm{Hg}$, hypercholesterolaemia as total serum cholesterol $\geqslant 250$ and $\geqslant 300 \mathrm{mg} / \mathrm{dl}$, overweight as body mass index $\geqslant 30 \mathrm{~kg} / \mathrm{m}^{2}$, and heavy drinking as alcohol intake $\geqslant 300 \mathrm{~g} /$ week.

Table 1 Correlation coefficients and linear regression slopes based on the original GCP data and a corrected dataset (see text)

\begin{tabular}{|c|c|c|c|c|c|c|c|c|c|}
\hline \multirow[b]{2}{*}{$\begin{array}{l}\text { Independent } \\
\text { variables (mean } \\
\text { values) }\end{array}$} & \multirow[b]{2}{*}{$\begin{array}{l}\text { Dependent variables (\% } \\
\text { prevalence of deviance) }\end{array}$} & & \multicolumn{3}{|c|}{ Original GCP data } & \multicolumn{3}{|c|}{ Corrected GCP dataset } & \multirow[b]{2}{*}{$\begin{array}{l}\text { Correlation } \\
\text { coefficients } \\
\text { according to } \\
\text { Rose et al }\end{array}$} \\
\hline & & & $\begin{array}{l}\text { Pearson } \\
\text { correlation } \\
\text { coefficients }\end{array}$ & $\begin{array}{l}\text { Slopes (linear } \\
\text { regression) }\end{array}$ & $\begin{array}{l}95 \% \\
\text { Confidence } \\
\text { intervals }\end{array}$ & $\begin{array}{l}\text { Pearson } \\
\text { correlation } \\
\text { coefficients }\end{array}$ & $\begin{array}{l}\text { Slopes (linear } \\
\text { regression) }\end{array}$ & $\begin{array}{l}95 \% \\
\text { Confidence } \\
\text { intervals }\end{array}$ & \\
\hline \multirow{6}{*}{$\begin{array}{l}\text { Systolic blood } \\
\text { pressure }\end{array}$} & Systolic hypertension & all & 0.97 & 1.71 & $1.51 / 1.91$ & 0.86 & 2.90 & $2.07 / 3.73$ & \multirow[t]{6}{*}{0.76} \\
\hline & $(\geqslant 140 \mathrm{~mm} \mathrm{Hg})$ & male & 0.95 & 1.93 & $1.61 / 2.24$ & 0.78 & 3.00 & $1.85 / 4.16$ & \\
\hline & & female & 0.98 & 1.48 & $1.33 / 1.64$ & 0.90 & 2.65 & $2.03 / 3.26$ & \\
\hline & Systolic hypertension & all & 0.91 & 0.67 & $0.53 / 0.82$ & 0.81 & 0.80 & $0.52 / 1.07$ & \\
\hline & $(\geqslant 160 \mathrm{~mm} \mathrm{Hg})$ & male & 0.94 & 0.63 & $0.52 / 0.75$ & 0.89 & 0.78 & $0.59 / 0.97$ & \\
\hline & & female & 0.90 & 0.77 & $0.59 / 0.96$ & 0.72 & 0.87 & $0.46 / 1.27$ & \\
\hline \multirow{6}{*}{$\begin{array}{l}\text { Diastolic blood } \\
\text { pressure }\end{array}$} & Diastolic hypertension & all & 0.97 & 2.35 & $2.06 / 2.63$ & 0.88 & 3.40 & $2.54 / 4.27$ & \multirow[t]{3}{*}{ - } \\
\hline & $(\geqslant 90 \mathrm{~mm} \mathrm{Hg})$ & male & 0.96 & 2.61 & $2.25 / 2.96$ & 0.84 & 3.55 & $2.46 / 4.64$ & \\
\hline & & female & 0.96 & 2.12 & $1.83 / 2.42$ & 0.87 & 2.91 & $2.10 / 3.72$ & \\
\hline & Diastolic hypertension & all & 0.96 & 1.38 & $1.20 / 1.56$ & 0.91 & 1.76 & $1.39 / 2.13$ & \multirow[t]{3}{*}{ - } \\
\hline & $(\geqslant 95 \mathrm{~mm} \mathrm{Hg})$ & male & 0.93 & 1.56 & $1.27 / 1.85$ & 0.85 & 1.88 & $1.32 / 2.44$ & \\
\hline & & female & 0.95 & 1.20 & $1.01 / 1.39$ & 0.88 & 1.44 & $1.06 / 1.81$ & \\
\hline \multirow[t]{6}{*}{ Cholesterol } & Hypercholesterolaemia & all & 0.95 & 0.89 & $0.75 / 1.03$ & 0.28 & 0.49 & $-0.32 / 1.31$ & \multirow[t]{3}{*}{ - } \\
\hline & $(\geqslant 250 \mathrm{mg} / \mathrm{dl})$ & male & 0.94 & 0.84 & $0.69 / 0.99$ & 0.40 & 0.62 & $-0.08 / 1.36$ & \\
\hline & & female & 0.95 & 0.89 & $0.74 / 1.04$ & 0.15 & 0.27 & $-0.59 / 1.14$ & \\
\hline & Hypercholesterolaemia & all & 0.83 & 0.38 & $0.26 / 0.50$ & 0.52 & 0.32 & $0.07 / 0.58$ & \multirow[t]{3}{*}{ - } \\
\hline & $(\geqslant 300 \mathrm{mg} / \mathrm{dl})$ & male & 0.68 & 0.28 & $0.13 / 0.42$ & 0.36 & 0.16 & $-0.07 / 0.40$ & \\
\hline & & female & 0.84 & 0.42 & $0.29 / 0.55$ & 0.46 & 0.33 & $0.27 / 0.64$ & \\
\hline \multirow{3}{*}{$\begin{array}{l}\text { Body mass } \\
\text { index }\end{array}$} & Overweight $\left(\geqslant 30 \mathrm{~kg} / \mathrm{m}^{2}\right)$ & all & 0.97 & 5.97 & $5.21 / 6.74$ & 0.86 & 9.03 & $6.44 / 11.62$ & \multirow[t]{3}{*}{0.78} \\
\hline & & male & 0.93 & 5.71 & $4.61 / 6.82$ & 0.78 & 7.29 & $4.50 / 10.08$ & \\
\hline & & female & 0.95 & 5.88 & $4.96 / 6.80$ & 0.75 & 8.94 & $5.18 / 12.71$ & \\
\hline \multirow[t]{6}{*}{ Alcohol intake } & Heavy drinking $(\geqslant 300$ & all & 0.95 & 0.18 & $0.15 / 0.21$ & 0.55 & 0.24 & $0.07 / 0.42$ & \multirow[t]{6}{*}{0.64} \\
\hline & $\mathrm{g} /$ week) & male & 0.98 & 0.19 & $0.17 / 0.21$ & 0.83 & 0.37 & $0.25 / 0.49$ & \\
\hline & & female & 0.83 & 0.14 & $0.10 / 0.19$ & 0.22 & 0.06 & $-0.07 / 0.20$ & \\
\hline & & all* & 0.77 & 13.44 & $8.02 / 18.88$ & 0.32 & 7.17 & $-2.90 / 17.24$ & \\
\hline & & male $^{\star}$ & 0.91 & 19.39 & $15.24 / 23.53$ & 0.73 & 20.70 & $11.41 / 29.99$ & \\
\hline & & femal ${ }^{\star}$ & 0.56 & 5.39 & $1.54 / 9.24$ & 0.24 & 2.53 & $-2.43 / 7.48$ & \\
\hline
\end{tabular}

${ }^{\star} \log (1+$ units $)$. 

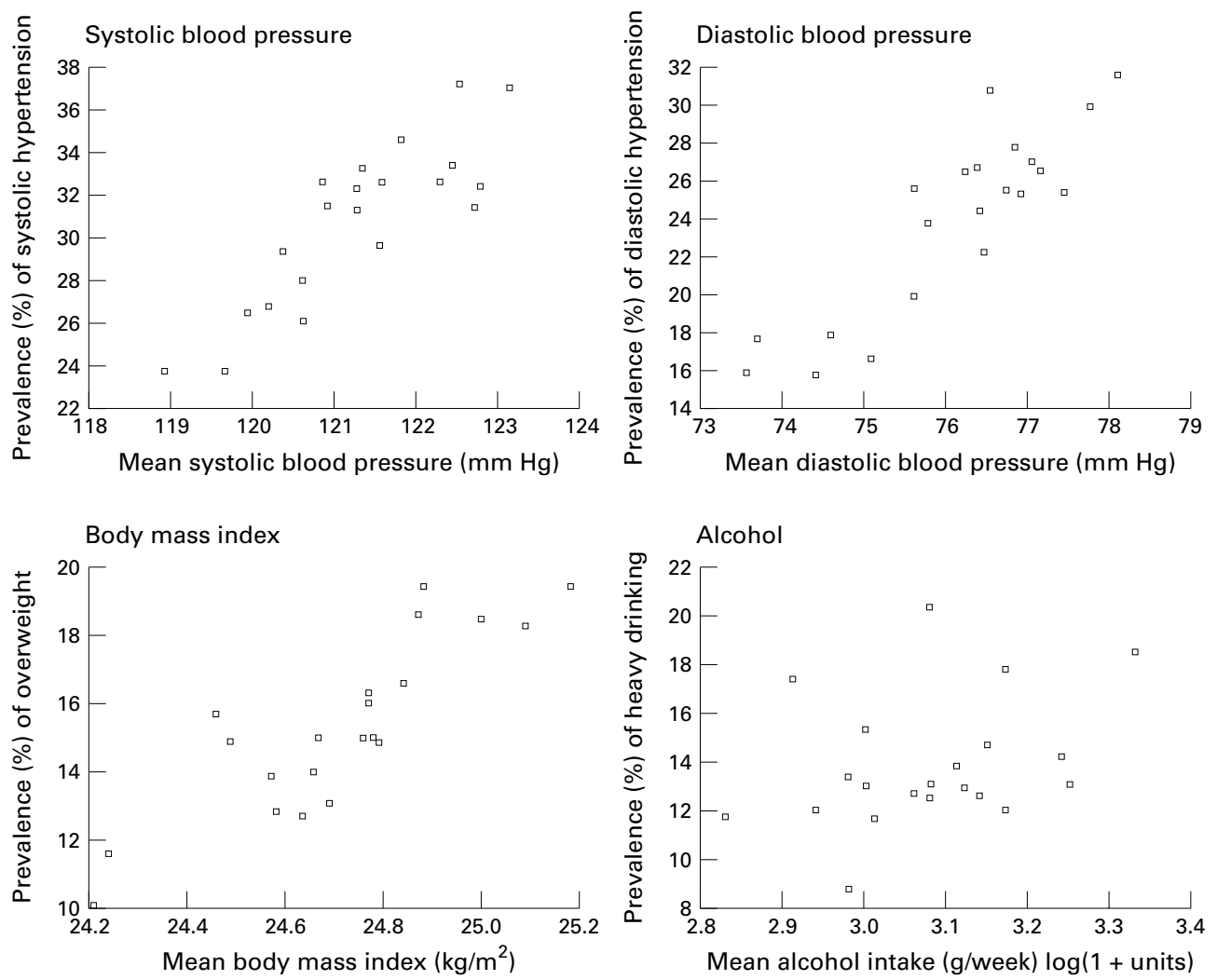

Figure 1 Scatter plots (corrected database) of the population means and the prevalence of deviant (high) values in seven study populations within Germany (1984-1988-1991): systolic hypertension ( $\geqslant 140 \mathrm{~mm} \mathrm{Hg}$ ), diastolic hypertension $(\geqslant 90 \mathrm{~mm} \mathrm{Hg})$, overweight $\left(\geqslant 30 \mathrm{~kg} / \mathrm{m}^{2}\right)$, and heavy drinking $(\geqslant 300 \mathrm{~g} / \mathrm{week})$.

Prevalence of the abnormal deviance was calculated in percentages.

Datasets of the corresponding population mean and disease prevalence were formed and the Pearson and Spearman correlation coefficients calculated (as both were very close only the Pearson coefficients are given). For alcohol consumption because of its highly skewed distribution a transformation $(\log (1+$ units $))$ was used in addition (25.6 to $35.6 \%$ did not indicate any relevant consumption of alcohol).

As the high values that constitute the prevalence of the disease also contribute to the calculation of the population mean, a certain degree of "autocorrelation" (Rose and Day ${ }^{3}$ ) enlarges the correlation coefficient. To correct for this effect, we also calculated the correlation coefficients after neglecting the high values (above the cut points as defined for prevalence) in the calculation of the population mean. Linear regression for each dataset was performed to predict the number of deviant people from the population mean. Correlation coefficients and regression lines for each calculation method (using the original as well as the corrected data) were compared to estimate the size of this effect, following Geoffrey Rose's approach closely.

\section{Results}

Twenty one datasets for each of the variables were analysed. Table 1 shows firstly, in the original dataset, the Pearson coefficients for the correlation between mean and prevalence. Very close relations can be seen with Pearson correlation coefficients varying from 0.97 , for example, for the body mass index to 0.77 for the log transformed alcohol consumption, all of them highly significant $(\mathrm{p}<0.01$, two tailed test).

Secondly, the Pearson correlation coefficients and the slopes of the linear regression lines for the corrected database are shown, where the effect of increased values (above defined cut points) has been removed from the calculation of the mean. This leads to a decrease in the size of previously "falsely" high correlation coefficients. At the same time the slopes of the corresponding regression lines

Table 2 Theroetical reduction in prevalence of disease after implementing population based preventive strategies, resulting in reduction of the population mean (corrected data, see text)

\begin{tabular}{|c|c|c|c|c|}
\hline Variable & Reduction in mean values & Prevalence (\%) of deviance & $\begin{array}{l}\text { Theoretical reduction in } \\
\text { prevalence (\%) according to } \\
\text { reduction in mean values }\end{array}$ & $\begin{array}{l}\text { Reduction (\%) according to } \\
\text { Rose et al, }{ }^{3} \text { see footnote }\end{array}$ \\
\hline Systolic blood pressure ( $\geqslant 140 \mathrm{~mm} \mathrm{Hg}$ ) & $5 \mathrm{~mm} \mathrm{Hg}$ & 31.4 & 14.5 & 5.0 \\
\hline Systolic blood pressure ( $\geqslant 160 \mathrm{~mm} \mathrm{Hg}$ ) & $5 \mathrm{~mm} \mathrm{Hg}$ & 9.7 & 4.0 & - \\
\hline Diastolic blood pressure $(\geqslant 90 \mathrm{~mm} \mathrm{Hg})$ & $2.5 \mathrm{~mm} \mathrm{Hg}$ & 24.6 & 8.5 & - \\
\hline Diastolic blood pressure ( $\geqslant 95 \mathrm{~mm} \mathrm{Hg})$ & $2.5 \mathrm{~mm} \mathrm{Hg}$ & 12.2 & 4.4 & - \\
\hline Body mass index $\left(\geqslant 30 \mathrm{~kg} / \mathrm{m}^{2}\right)$ & $1 \mathrm{~kg} / \mathrm{m}^{2}$ & 15.7 & 9.0 & 6.9 \\
\hline Alcohol intake ( $\geqslant 300 \mathrm{~g} / \mathrm{week})$ & $15 \mathrm{~g} /$ week & 13.8 & 3.7 & 4.5 \\
\hline
\end{tabular}

${ }^{\star}$ Based on table III in Rose $e t$ al : for alcohol intake the value used by Rose of $0.24 \%$ per $\mathrm{ml} /$ week has been increased by 0.8 to obtain $\mathrm{g} /$ week. 
increase in comparison with the slopes in the original data. This can be explained by the different effects that the treatment of high values in our case has on the independent and dependent variable. While the spread of the independent variable, the population mean, is reduced after neglecting the high values in its calculation, the spread of the dependent variable, the prevalence of disease, remains unchanged. This leads to an increase of the slope. An exemption is the relation of hypercholesterolaemia and cholesterol, and heavy drinking and alcohol consumption (log transformed).

The new correlation coefficients for systolic blood pressure are 0.86 and 0.81 respectively, for diastolic blood pressure 0.88 and 0.91 , and for body mass index 0.86 . Their size still suggests a close relation between the height of the population mean and the frequency of the corresponding disease states hypertension and overweight. There is only a weak relation between hypercholesterolaemia and cholesterol and between mean alcohol intake and prevalence of heavy drinking. In this case the overall correlation was mainly attributable to the higher values of the distribution leading to a considerable overestimation.

Figure 1 shows the relation between prevalence of selected disease states and means of the population neglecting the high values for each variable as a scatter plot. In the studied range there exists a linear, positive relation between prevalence of hypertension and mean systolic and diastolic pressure, between prevalence of overweight and mean body mass index, however not between heavy drinking and mean alcohol intake per week if the logarithmic transformation of the data is used.

Table 2 shows the theoretical change in prevalence of disease after implementing population based preventive strategies with a defined effect. Reducing the mean systolic blood pressure of the population by $5 \mathrm{~mm} \mathrm{Hg}$, a reduction in prevalence of systolic hypertension can be observed that amounts to $14.5 \%$ for the lower borderline of $\geqslant 140 \mathrm{~mm}$ $\mathrm{Hg}$ and to 4.0 for a borderline $\geqslant 160 \mathrm{~mm} \mathrm{Hg}$. As can be expected the effect is stronger for lowering the diastolic blood pressure. Therefore we choose a reduction of the population mean only by $2.5 \mathrm{~mm} \mathrm{Hg}$ leading to a fall in the prevalence of diastolic hypertension of $8.5 \%$ (borderline $\geqslant 90 \mathrm{~mm} \mathrm{Hg}$ ) and of $4.4 \%$ (borderline $\geqslant 95 \mathrm{~mm} \mathrm{Hg}$ ) respectively. This is a substantial decrease, as, for example, the prevalence of diastolic hypertension $\geqslant 95 \mathrm{~mm}$ $\mathrm{Hg}$ in our study ranged between $7 \%$ and $16 \%$ (see appendix 1). A reduction of the same order was found for overweight and body mass index $\left(9.0 \%\right.$ for a decrease of $1 \mathrm{~kg} / \mathrm{m}^{2}$ in population mean), and for heavy drinking and weekly alcohol intake (3.7\% for a weekly alcohol intake reduced by $15 \mathrm{~g})$.

\section{Discussion}

While we observed high correlation coefficients for all variables in the uncorrected database, results changed after eliminating the contribution of values increased above defined border-
KEY POINTS

- It is possible to shift the risk distribution of a population to a lower range thereby reducing the number of people at risk.

- Our data show this relation for physiological parameters such as arterial blood pressure and body mass index.

- These findings support Rose's concept of the great potential of the population strategy.

lines. Yet the relations between blood pressure and hypertension as well as between body mass index and overweight were still very strong and even closer than those found by Rose and Day, whereas the relation between heavy drinking and weekly alcohol intake was somewhat weaker especially after logarithmic transformation (table 1). We could also confirm a weak relation between hypercholesterolaemia (cut point $\geqslant 300 \mathrm{mg} / \mathrm{dl}$ ) and cholesterol (correlation coefficient 0.52 versus 0.83 at $p<0.01$ for the uncorrected data).

Table 2 shows the results found by Rose and $\mathrm{Day}^{3}$ in comparison with our findings. The percentage reductions they calculated from a very different set of populations across the world compare well for alcohol intake and body mass index but, in the German data, are exceeded clearly for systolic blood pressure. This is probably attributable to the higher age range in the German population (ages 25-69) and therefore much higher prevalence of hypertension - that is, $31.4 \%$ for systolic borderline hypertension (see table 2 ). The relative change of prevalence therefore is reasonably similar, for example, $46.2 \%$ in our data compared with $33.3 \%$ in the corrected data of Rose.

A reason for observed differences in all variable pairs is the studied range of values and the concomitant precision of the estimates. While Rose and Day examined widely different populations with great variations in population mean and prevalence rates ranging from $0 \%$ to $50 \%$, our study populations were relatively homogenous, as they all came from the same cultural background. The range of mean systolic blood pressure in Rose's study varied from 96 to $132 \mathrm{~mm} \mathrm{Hg}$. In our study we examined only the range between 124 and $130 \mathrm{~mm} \mathrm{Hg}$. This can account for a different slope in the calculation of the regression line. The same applies to the variables "weekly alcohol intake" and "body mass index". Our database covers only $15 \%$ respectively $8 \%$ of the range of the means of study populations as available to Rose.

A further source of bias is the method of measurement. While blood pressure and body mass index were measured by trained personnel, data on alcohol intake were self reported. As drinking of alcohol is subject to social stigma, there might be a tendency to underestimate your weekly alcohol consumption. This applies especially to heavy drinkers. Another reason why we found a weaker relation between weekly alcohol intake and prevalence of heavy drinking might be the relatively short duration for a radical 


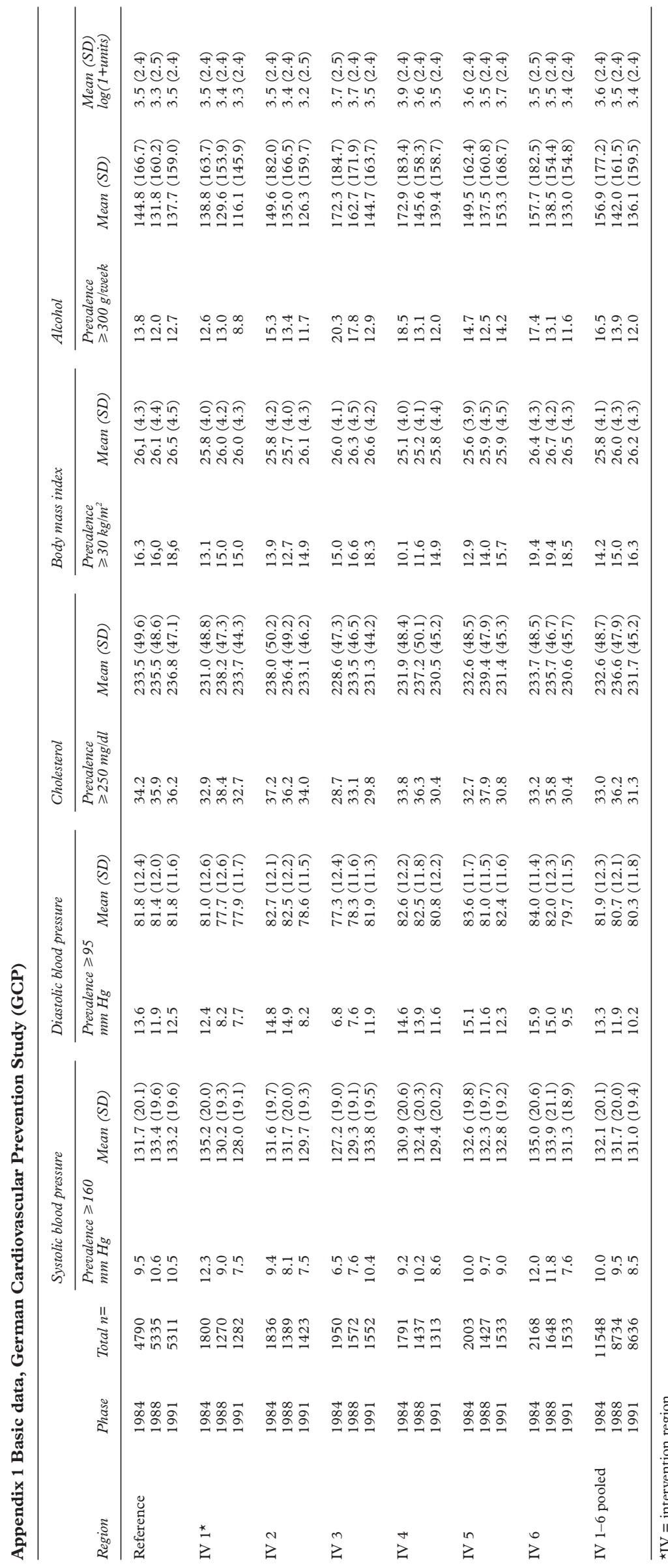

preventive strategy. The group of heavy drinkers probably comprises a high percentage of addicted alcoholics who cannot quit or reduce alcohol intake easily. In this case the population's risk distribution does not simply shift to the left but also increases skewness to the right. This phenomenon can lead to the observed independence of the studied variables. In this case the incidence rate of alcoholism would be a better estimate of short-term changes.

Despite the possible sources of bias discussed above, our study basically yields the same results as were deduced by Rose, to a degree that is rather astonishing, especially as a mixed intervention strategydirected to the general population as well as to the high risk people - has been applied in the GCP. Earlier analyses ${ }^{9} 10$ even seem to show that the high risk oriented GCP intervention had a stronger impact than the population strategy. For example, using logistic regression coefficients for West European men from the ERICA Study, ${ }^{11}$ reductions of the means of systolic blood pressure and total cholesterol by $2 \%$, and of smoking by $7 \%$ as achieved in the GCP, led to a lowering of the six year CHD mortality by about $10 \%$. In comparison a simulated but carefully realistic reduction of the prevalence of these risk factors by $10 \%$ resulted in a decrease of the CVD mortality between $10 \%$ and $20 \%$ depending on the borderlines chosen.

We believe to have shown that differences induced artificially through active intervention may behave like differences between free living populations, and follow closely Rose's hypothesis stating that "the tail belongs to the body". ${ }^{3}$ It therefore is plausible that multi-factorially determined parameters such as arterial blood pressure and body mass index can be influenced by what is considered "normal" in a society. If most people begin to increase their amount of exercising or reduce their salt and fat intake, this will have an impact even on those who do not actively try to change their lifestyle. As was advocated by Rose, the implications for society and the medical community are great. We have to accept a collective responsibility for disease and abnormality by what we consider normality in our life style. While this might be more readily accepted for behavioural parameters such as aggression, it also holds true for physiological parameters.

Funding: none.

Conflicts of interests: none.

1 Shaper AG. Blood pressure studies in East Africa. In: Stamler J, Stamler R, Pulman TN, eds. The epidemiol-
ogy of hypertension. New York: Grune and Stratten, 1967:139-45.

2 The Intersalt Cooperative Research Group. INTERSALT. An international study of electrolyte excretion and blood pressure; results for 24 hour urinary sodium and potassium. BMF 1988;297:319-28.

3 Rose G, Day S. The population mean predicts the number of deviant individuals. BMF 1990;301:1031- 


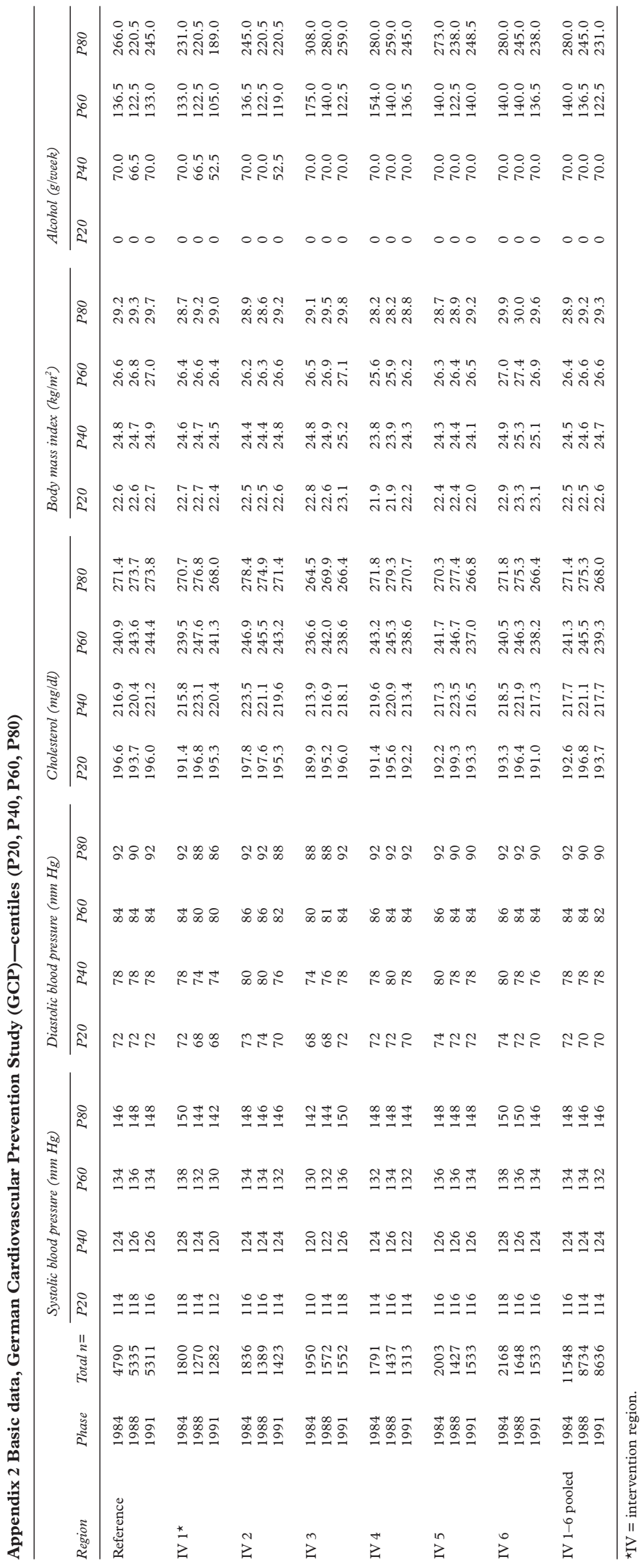

4 Rose G. Sick individuals and sick populations. Int $\mathcal{f}$

Epidemiol 1985;14:32-8. (a)

ethical considerations. Ann Med 1987;21:409-13.
6 Hoffmeister H, Mensink GBM, Stolzenberg H, et al. Reduction of coronary heart disease risk factors in the German Cardiovascular Prevention Study. Prev Med 1996; 25:135-45

7 GCP Study Group. The German Cardiovascular Prevention Study (GCP): design and methods. Eur Heart $\mathcal{F}$ 1988;9: 1058-66.

8 Forschungsverbund DHP (Hrsg). Die Deutsche HerzKreislauf-Präventionsstudie, Design und Ergebnisse. Bern: Verlag Hans Huber, 1998.

9 Laaser U, Breckenkamp J, Meyer S, et al. The results of the GCP-Intervention for hypertension and hypercholesterolemia in the high-risk-groups. Zeitschrift für Gesundheitswissemchaften 1995;3:242-51.

10 Meyer S, Babitsch B, Schmitt-Thomas B, et al. The potential of intervention for coronary heart disease in Germany: trend projections based on the German Cardiovascular Prevention Study (GCP). Informatik, Biometrie und EpidePrevention Study (GCP). Informatik, Biometrie und

11 miologie in Medizin und Biologie 1998;29:175-85 disease in Europe. The 2nd report of the WHO-ERICA Project. European Heart fournal 1991;12:291-7. 